\title{
A proposed nomenclature for cell wall proteins of Clostridium difficile
}

Correspondence

Neil F. Fairweather

n.fairweather@imperial.ac.uk

Received 1 December 2010

Accepted 14 January 2011

\author{
Robert P. Fagan, ${ }^{1}$ Claire Janoir, ${ }^{2}$ Anne Collignon, ${ }^{2}$ Paola Mastrantonio, ${ }^{3}$ \\ lan R. Poxton ${ }^{4}$ and Neil F. Fairweather ${ }^{1}$ \\ ${ }^{1}$ Division of Cell and Molecular Biology, Centre for Molecular Microbiology and Infection, Imperial \\ College London, London SW7 2AZ, UK \\ ${ }^{2}$ Université de Paris-Sud XI, USC INRA EA 4043, Faculté de Pharmacie, Châtenay-Malabry Cedex, \\ France \\ ${ }^{3}$ Department of Infectious, Parasitic and Immune-Mediated Diseases, Istituto Superiore di Sanità, \\ Viale Regina Elena 299, 00161 Rome, Italy \\ ${ }^{4}$ Medical Microbiology, Centre for Infectious Diseases, University of Edinburgh College of Medicine \\ and Veterinary Medicine, Edinburgh EH16 4SB, UK
}

\begin{abstract}
Strains of Clostridium difficile produce a number of surface-localized proteins, including the Slayer proteins (SLPs) and other proteins that have suspected roles in pathogenesis. During the Third International C. difficile Symposium (Bled, Slovenia, September 2010) discussions were held on standardization of nomenclature. Gene designations were proposed for the large family of cell wall proteins that are paralogues of the SLP and contain putative cell wall binding motifs. This paper summarizes the agreed nomenclature, which we hope will be used by research groups currently active in the field.
\end{abstract}

\section{INTRODUCTION}

Clostridium difficile is now recognized as an important bacterial pathogen, particularly in health-care settings where it can cause serious enteric disease (Bartlett, 2006; Rupnik et al., 2009). While symptoms of disease are mediated largely by two potent cytotoxins, toxin A (TcdA) and toxin B (TcdB) (Kuehne et al., 2010; Lyras et al., 2009), many other factors are thought to be essential for colonization of the enteric system to allow toxin production and eventual sporulation. C. difficile produces many surface-localized proteins which may contribute to colonization through, for example, direct adherence to host cells or by competition with the resident microbiota. Early studies showed that diverse strains of $C$. difficile produced two major surface-associated proteins that could be extracted from the cell by treatment with EDTA, urea or low-pH glycine treatments (Cerquetti et al., 1992; Kawata et al., 1984; McCoubrey \& Poxton, 2001; Sharp \& Poxton, 1988; Takeoka et al., 1991). These proteins, which migrated on SDS-PAGE with apparent molecular masses of between 35 and $55 \mathrm{kDa}$, displayed the ability to form a twodimensional array which was visible by electron microscopy (Cerquetti et al., 2000; Kawata \& Masuda, 1984), an inherent property of surface-layer (S-layer) proteins (SLPs) from Bacteria and Archaea.

Abbreviations: CWPs, cell wall proteins; SLPs, S-layer proteins.
Genetic studies have identified several important points. Firstly, the two dominant proteins observed on the surface of a variety of strains were the result of proteolytic processing of SlpA, the product of a single gene termed slpA (Calabi et al., 2001; Karjalainen et al., 2001). These proteins were subsequently termed SLPs. Secondly, the differences in mobility of these proteins between strains, as visualized by SDS-PAGE, were due to differences in the lengths of the $\operatorname{slp} A$ genes, resulting in antigenically distinct forms of the SLPs. Thirdly, a family of genes (paralogues) related to $s l p A$ was identified in the genome of strain 630 (Calabi et al., 2001; Karjalainen et al., 2001; Savariau-Lacomme et al., 2003; Sebaihia et al., 2006). Members of this family, which comprises 29 genes, all contain three copies of the Pfam 04122 motif, which is a complex motif annotated as 'putative cell wall binding repeat 2'. The idea was proposed (Karjalainen et al., 2001) that these Pfam motifs mediate binding of the proteins encoded by these paralogues to the underlying cell wall. In some cases, these proteins carry a second domain which specifies a known or putative function. The best characterized examples are Cwp84 (Janoir et al., 2007), a protease that cleaves the SlpA precursor (Dang et al., 2010; Kirby et al., 2009) and which has degradative activity on a variety of host cell extracellular matrix proteins (Janoir et al., 2007), Cwp66, a putative adhesin (Waligora et al., 2001), and CwpV, a phase-variable protein (Emerson et al., 2009). 
With an increasing number of research groups working on $C$. difficile and the advent of genome sequences that are uncovering increasing diversity between $C$. difficile strains, the need for a unified nomenclature of $C$. difficile S-layer and cell wall proteins is apparent. A similar situation existed a few years ago in regard to the nomenclature of the large clostridial cytotoxins, and a unified nomenclature was proposed (Rupnik et al., 2005) and has been universally adopted.

\section{PROPOSED NOMENCLATURE}

\section{SLPs}

All strains of $C$. difficile examined to date express two predominant proteins on the cell wall, which form the major components of the S-layer. The encoding gene, which appears to have a conserved genomic location between all strains studied to date, has been named $s l p A$. The precursor protein is termed SlpA, and the mature proteins produced by the action of the protease Cwp84 are termed the HMW (high molecular weight) SLP and the LMW (low molecular weight) SLP. The HMW SLP contains three Pfam 04122 'putative cell wall binding repeat 2' motifs while the LMW SLP shows a high degree of antigenic variation between strains. We suggest that the prefix slp be reserved for those genes whose products have been shown experimentally to form a two-dimensional array, and not used for gene products found within the S-layer, as this could vary depending on the technique used for extraction of SLPs.

\section{Cell wall proteins}

In $C$. difficile 630, a family of 29 genes containing three Pfam 04122 motifs was identified. These genes were originally given the prefix 'orf1', 'orf2', etc. (Calabi et al., 2001; Karjalainen et al., 2001), but due to simultaneous publication, the genes were numbered differently. In addition, the genes cwp66 and cwp84 were individually named according to their molecular masses (Karjalainen et al., 2001). Following this convention, some other genes (Wright et al., 2005) were given a ' $c w p$ ' prefix (Emerson \& Fairweather, 2009; Wright et al., 2008).

Ordinarily, a gene family would be named using only letters, e.g. $s l p A$ and $c w p V$. However, as there are over 26 paralogues, this is not possible. In addition, some names are in common use and we recommend keeping these. We propose that all members of the gene family containing Pfam 04122 motifs be termed CWPs, 'clostridial wall proteins' or more aptly 'cell wall proteins' and that the genes be given the prefix cwp. The exception is $\operatorname{slp} A$, which, although a member of this gene family, has a clearly established name which relates to its function as an SLP. Where an existing name has been published and has been generally accepted, that name should remain in use. To date these are cwp84, cwp66, cwpV and cwp2. All other $c w p$ genes have been assigned a number as outlined in Table 1 . The ORF designation with a CD prefix given upon annotation of strain 630 is also shown. The vast majority of the cwp genes are conserved between 630 and R20291, a recently isolated ribotype 027 strain which has been sequenced at the genome level (Stabler et al., 2009). Genome sequencing of further $C$. difficile strains will undoubtedly reveal new members of the $c w p$ gene family. We suggest that the naming be continued numerically, i.e. the next $c w p$ gene identified should be named cwp30.

Several of the CWPs contain a passenger domain that may specify a function. The majority of these have not been demonstrated experimentally, but are based on the presence of motifs. The putative functional motifs and the architectures of members of the CWP family are shown in Fig. 1.

Table 1. Nomenclature of CWPs of C. difficile

The CWP family is defined as possessing Pfam 04122 'putative cell wall binding repeat 2 ' motifs.

\begin{tabular}{|c|c|c|}
\hline Gene name ${ }^{\star}$ & Gene number $\dagger$ & Mol. mass $\ddagger(\mathrm{kDa})$ \\
\hline $\operatorname{slp} A$ & CD2793 & 76.1 \\
\hline$c w p 2$ & CD2791 & 66.5 \\
\hline cwp66 & CD2789 & 66.8 \\
\hline cwp84 & CD2787 & 87.3 \\
\hline$c w p 5$ & CD2786 & 57.2 \\
\hline cwp6 & CD2784 & 73.0 \\
\hline$c w p 7$ & CD2782 & 39.3 \\
\hline$c w p 8$ & CD2799 & 68.5 \\
\hline cwp9 & CD2798 & 52.5 \\
\hline cwp10 & CD2796 & 67.0 \\
\hline cwp11 & CD2795 & 58.7 \\
\hline cwp12 & CD2794 & 57.5 \\
\hline cwp13 & CD1751 & 87.2 \\
\hline cwp14 & CD2735 & 51.4 \\
\hline$c w p V$ & CD0514 & 166.7 \\
\hline cwp16 & CD1035 & 74.7 \\
\hline cwp17 & CD1036 & 74.2 \\
\hline cwp18 & CD1047 & 37.4 \\
\hline cwp19 & CD2767 & 77.8 \\
\hline cwp20 & CD1469 & 111.1 \\
\hline cwp21 & CD3192 & 61.1 \\
\hline cwp22 & CD2713 & 72.0 \\
\hline cwp23 & CD1803 & 63.8 \\
\hline cwp24 & CD2193 & 51.3 \\
\hline cwp25 & CD0844 & 33.8 \\
\hline cwp26 & CD1233 & 52.0 \\
\hline cwp27 & CD0440 & 41.0 \\
\hline cwp28 & CD1987 & 51.7 \\
\hline$c w p 29$ & CD2518 & 50.0 \\
\hline
\end{tabular}

${ }^{\star}$ There is no $c w p 1$ gene. Proteins have identical names, but with a capitalized first letter and not italicized. Gene names in the current literature are: $\operatorname{slp} A$ (Calabi et al., 2001), $c w p 2$ and $c w p V$ (Emerson et al., 2009), cwp66 (Waligora et al., 2001) and cwp84 (Karjalainen et al., 2001). $\dagger$ Gene number according to Sebaihia et al. (2006). All genes except cwp29 have paralogues in R20291.

$\ddagger$ Predicted molecular mass of protein prior to any processing event. 


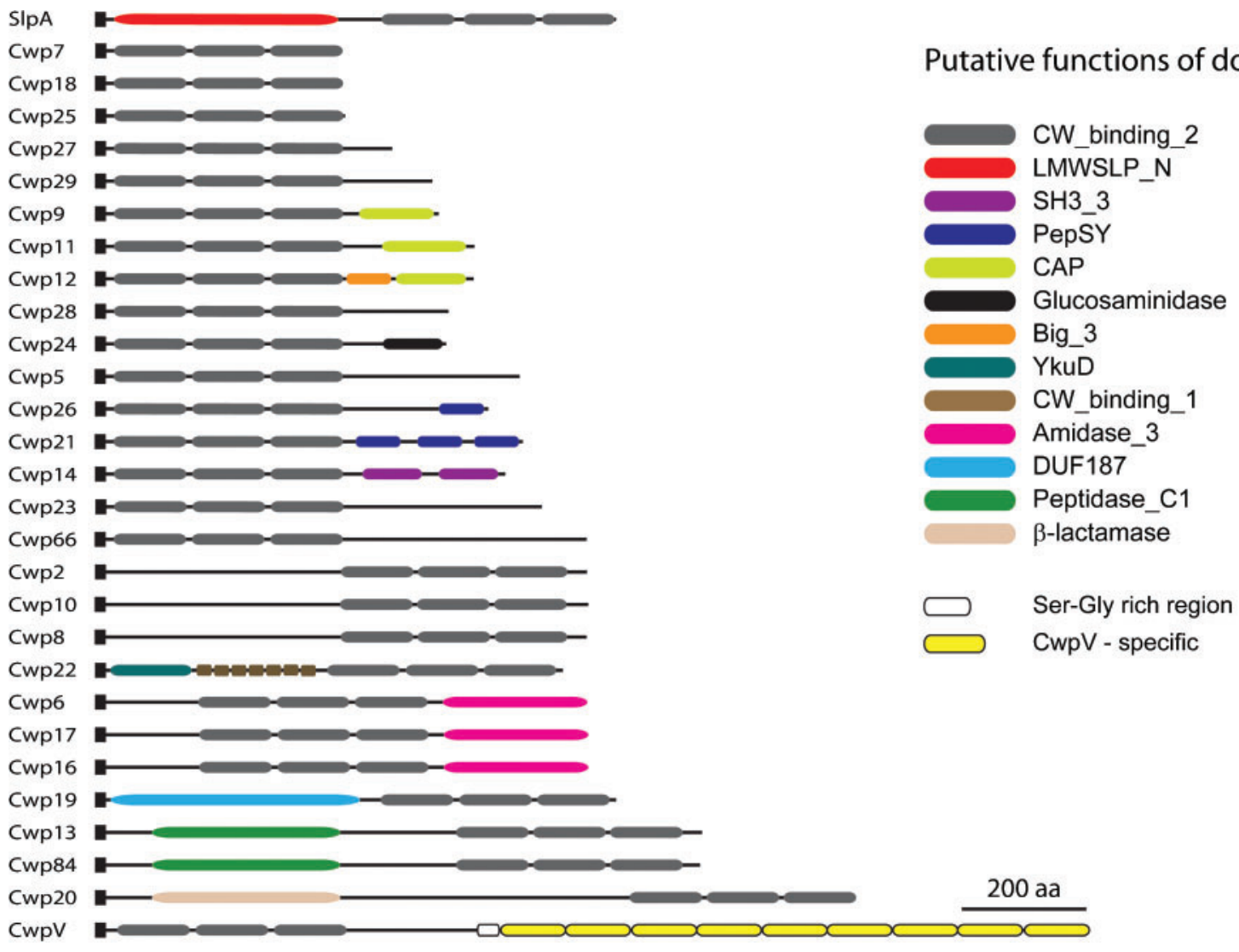

Fig. 1. Domain architecture of the CWP family. The functional domains contained within each protein were determined by analysis using Pfam (http://pfam.sanger.ac.uk/) and are as follows: CW_binding 2 (PF04122), LMWSLP_N (PF12211), SH3_3 (PF08239), PepSY (PF03413), CAP (PF00188), Glucosaminidase (PF01832), Big_3 (PF07523), YkuD (PF03734), CW_binding_1 (PF01473), Amidase_3 (PF01520), DUF187 (PF02638), Peptidase_C1 (PF00112) and $\beta$-lactamase (PF00144). All proteins contain a predicted $\mathrm{N}$-terminal signal peptide (black box).

\section{Other surface-localized proteins}

C. difficile genomes encode a number of putative surfacelocalized proteins in addition to the CWP family. Some of these have been characterized at the molecular level, for example $f b p 68$ encoding a fibronectin-binding protein (Hennequin et al., 2003). At least one sortase gene has been identified in 630 and R20291 genomes and a number of putative sortase substrates have also been identified. We suggest that any names assigned to these genes and proteins remain unchanged and that newly characterized genes, for example the sortase substrates, be named by the group who first describe their properties.

\section{REFERENCES}

Bartlett, J. G. (2006). Narrative review: the new epidemic of Clostridium difficile-associated enteric disease. Ann Intern Med 145, 758-764.

Calabi, E., Ward, S., Wren, B., Paxton, T., Panico, M., Morris, H., Dell, A., Dougan, G. \& Fairweather, N. (2001). Molecular characterization of the surface layer proteins from Clostridium difficile. Mol Microbiol 40, 1187-1199.

Cerquetti, M., Pantosti, A., Stefanelli, P. \& Mastrantonio, P. (1992). Purification and characterization of an immunodominant $36 \mathrm{kDa}$ antigen present on the cell surface of Clostridium difficile. Microb Pathog 13, 271-279.

Cerquetti, M., Molinari, A., Sebastianelli, A., Diociaiuti, M., Petruzzelli, R., Capo, C. \& Mastrantonio, P. (2000). Characterization of surface layer proteins from different Clostridium difficile clinical isolates. Microb Pathog 28, 363-372.

Dang, T. H., de la Riva, L., Fagan, R. P., Storck, E. M., Heal, W. P., Janoir, C., Fairweather, N. F. \& Tate, E. W. (2010). Chemical probes of surface layer biogenesis in Clostridium difficile. ACS Chem Biol 5, 279285.

Emerson, J. \& Fairweather, N. F. (2009). Surface structures of $C$. difficile and other clostridia. In Clostridia - Molecular Biology in the Post-genomic Era, pp. 157-167. Edited by H. Bruggemann \& G. Gottschalk. Norfolk, UK: Caister Academic Press.

Emerson, J. E., Reynolds, C. B., Fagan, R. P., Shaw, H. A., Goulding, D. \& Fairweather, N. F. (2009). A novel genetic switch controls phase variable expression of $\mathrm{CwpV}$, a Clostridium difficile cell wall protein. Mol Microbiol 74, 541-556. 
Hennequin, C., Janoir, C., Barc, M.-C., Collignon, A. \& Karjalainen, T. (2003). Identification and characterization of a fibronectin-binding protein from Clostridium difficile. Microbiology 149, 2779-2787.

Janoir, C., Péchiné, S., Grosdidier, C. \& Collignon, A. (2007). Cwp84, a surface-associated protein of Clostridium difficile, is a cysteine protease with degrading activity on extracellular matrix proteins. J Bacteriol 189, 7174-7180.

Karjalainen, T., Waligora-Dupriet, A.-J., Cerquetti, M., Spigaglia, P., Maggioni, A., Mauri, P. \& Mastrantonio, P. (2001). Molecular and genomic analysis of genes encoding surface-anchored proteins from Clostridium difficile. Infect Immun 69, 3442-3446.

Kawata, T. \& Masuda, K. (1984). Electron-microscopy of a regular array in the cell wall of Clostridium difficile. J Electron Microsc (Tokyo) 33, 297.

Kawata, T., Takeoka, A., Takumi, M. \& Masuda, K. (1984). Demonstration and preliminary characterisation of a regular array in the cell wall of Clostridium difficile. FEMS Microbiol Lett 24, 323328.

Kirby, J. M., Ahern, H., Roberts, A. K., Kumar, V., Freeman, Z., Acharya, K. R. \& Shone, C. C. (2009). Cwp84, a surface-associated cysteine protease, plays a role in the maturation of the surface layer of Clostridium difficile. J Biol Chem 284, 34666-34673.

Kuehne, S. A., Cartman, S. T., Heap, J. T., Kelly, M. L., Cockayne, A. \& Minton, N. P. (2010). The role of toxin A and toxin B in Clostridium difficile infection. Nature 467, 711-713.

Lyras, D., O'Connor, J. R., Howarth, P. M., Sambol, S. P., Carter, G. P., Phumoonna, T., Poon, R., Adams, V., Vedantam, G. \& other authors (2009). Toxin B is essential for virulence of Clostridium difficile. Nature 458, 1176-1179.

McCoubrey, J. \& Poxton, I. R. (2001). Variation in the surface layer proteins of Clostridium difficile. FEMS Immunol Med Microbiol 31, 131-135.

Rupnik, M., Dupuy, B., Fairweather, N. F., Gerding, D. N., Johnson, S., Just, I., Lyerly, D. M., Popoff, M. R., Rood, J. I. \& other authors (2005).
Revised nomenclature of Clostridium difficile toxins and associated genes. J Med Microbiol 54, 113-117.

Rupnik, M., Wilcox, M. H. \& Gerding, D. N. (2009). Clostridium difficile infection: new developments in epidemiology and pathogenesis. Nat Rev Microbiol 7, 526-536.

Savariau-Lacomme, M. P., Lebarbier, C., Karjalainen, T., Collignon, A. \& Janoir, C. (2003). Transcription and analysis of polymorphism in a cluster of genes encoding surface-associated proteins of Clostridium difficile. J Bacteriol 185, 4461-4470.

Sebaihia, M., Wren, B. W., Mullany, P., Fairweather, N. F., Minton, N., Stabler, R., Thomson, N. R., Roberts, A. P., Cerdeño-Tárraga, A. M. \& other authors (2006). The multidrug-resistant human pathogen Clostridium difficile has a highly mobile, mosaic genome. Nat Genet 38, 779-786.

Sharp, J. \& Poxton, I. R. (1988). The cell wall proteins of Clostridium difficile. FEMS Microbiol Lett 55, 99-104.

Stabler, R. A., He, M., Dawson, L., Martin, M., Valiente, E., Corton, C., Lawley, T. D., Sebaihia, M., Quail, M. A. \& other authors (2009). Comparative genome and phenotypic analysis of Clostridium difficile 027 strains provides insight into the evolution of a hypervirulent bacterium. Genome Biol 10, R102.

Takeoka, A., Takumi, K., Koga, T. \& Kawata, T. (1991). Purification and characterization of $S$ layer proteins from Clostridium difficile GAI 0714. J Gen Microbiol 137, 261-267.

Waligora, A. J., Hennequin, C., Mullany, P., Bourlioux, P., Collignon, A. \& Karjalainen, T. (2001). Characterization of a cell surface protein of Clostridium difficile with adhesive properties. Infect Immun 69, 2144-2153.

Wright, A., Wait, R., Begum, S., Crossett, B., Nagy, J., Brown, K. \& Fairweather, N. (2005). Proteomic analysis of cell surface proteins from Clostridium difficile. Proteomics 5, 2443-2452.

Wright, A., Drudy, D., Kyne, L., Brown, K. \& Fairweather, N. F. (2008). Immunoreactive cell wall proteins of Clostridium difficile identified by human sera. J Med Microbiol 57, 750-756. 